\title{
THE ACTIVATION OF ALUMINIUM BY INDIUM IONS IN CHLORIDE, BROMIDE AND IODIDE SOLUTIONS
}

\author{
Carmel B. Breslin* and William M. Carroll ${ }^{\dagger}$ \\ * Department of Chemistry, Maynooth College, Co. Kildare, Ireland \\ † Department of Chemistry, University College, Galway, Ireland
}

\begin{abstract}
The corrosion and passive behaviour of aluminium in chloride, bromide and iodide solutions in the absence and presence of indium, as activator ions, was investigated using electrochemical techniques. Pit formation mechanisms for aluminium in chloride-, bromide- and iodide-containing solutions appeared to be similar with the caveat that, in the case of iodide anions, liberated iodine attacked the base metal leading to destabilization of the forming film. In addition, the formation of iodic and hypoiodous acids gave rise to the build-up of a highly aggressive pit solution which inhibited repassivation. The difference in the activity of the halide anions was evident also on activation of the aluminium surface by indium ions introduced into the working solution. Greater adsorption of bromide and iodide anions at flawed areas reduced the rate and efficiency of activator deposition at the aluminium surface, with the result that the rate at which the surface was activated was reduced. Activation appeared, also, to be more permanent in chloride-containing electrolytes.
\end{abstract}

\section{INTRODUCTION}

THE PITTING behaviour of aluminium has been studied extensively in environments containing chloride as the aggressive ions, ${ }^{1-6}$ presumably because chlorides are most commonly encountered in environments such as sea water, chemical plants, and pulp and paper processing. These investigations have provided considerable insight into the process of pitting attack, and at the present time a number of pit initiation theories exist, ranging from adsorption of chloride at the interface, ${ }^{1,7,8}$ its involvement as a chemical reaction partner, ${ }^{2}$ to transient exposure of bare aluminium in a crack-heal process ${ }^{9,10}$ and solid state cohesion theory. ${ }^{11}$ Very few reports on the pitting behaviour of metals in bromide or iodide electrolytes are available, and where such information has been reported it has been concerned mainly with stainless steels ${ }^{12}$ or with the stoichiometry of attack. ${ }^{13}$ The performance of materials in moist iodine vapours at low temperatures has been studied ${ }^{14}$ and these results show that iodine is very aggressive to $\mathrm{Ni}-\mathrm{Cr}-\mathrm{Fe}$ alloys with a low Mo content. All studies concerned with the activation of aluminium by the activator elements, indium, gallium, mercury, etc., have been carried out in either chloride or hydroxide environments. ${ }^{15-18}$

The objective of the present study is to provide information on the process of the pitting of aluminium in bromide and iodide environments and the influence that liberated iodine may have on the pitting reactions. The influence of bromide, iodide and chloride on the electrochemical behaviour of aluminium activated by indium ions in solution is also investigated, enabling a greater understanding of the effects of halide anions on aluminium. 


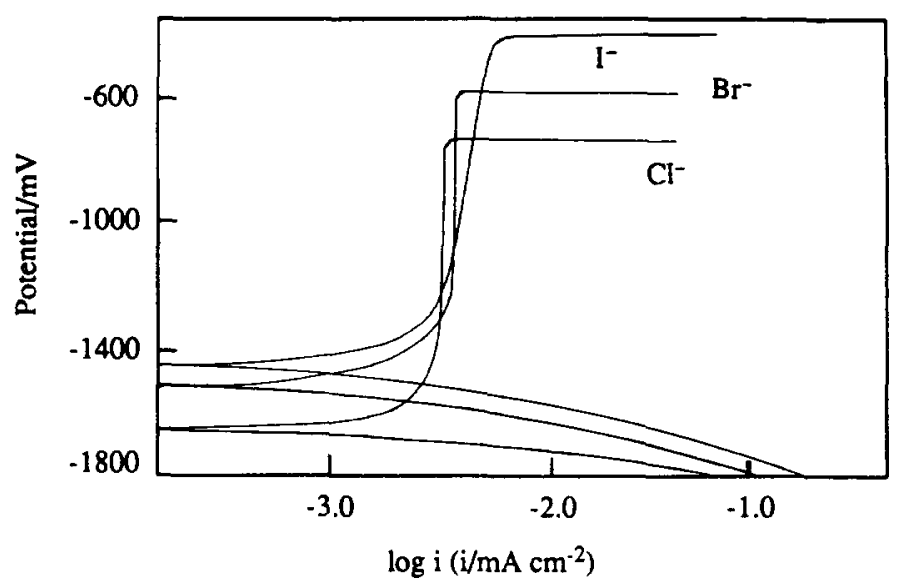

FIG. 1. Potentiodynamic polarization plots of $99.999 \%$ aluminium in $0.5 \mathrm{M} \mathrm{NaCl}, 0.5 \mathrm{M}$ $\mathrm{NaBr}$ and $0.5 \mathrm{M} \mathrm{NaI}$ solutions all adjusted to a $\mathrm{pH}$ of 7.0 .

\section{EXPERIMENTAL METHOD}

Aluminium test specimens of $99.999 \%$ purity, were mounted in a beeswax-colophony resin mixture with a circular area of $1 \mathrm{~cm}^{2}$ exposed to the test solution. Surface preparation of the test specimens and the electrochemical apparatus is described elsewhere. ${ }^{19}$ Test solutions were prepared from AnalaR grade reagents and distilled water. The $\mathrm{pH}$ of the test solutions was adjusted using $\mathrm{NaOH}$ or the appropriate acid, $\mathrm{HCl}, \mathrm{HBr}$ or $\mathrm{HI}$.

Reproducible and consistent potentiostatic current-time curves were enabled by prepolarizing the aluminium test samples at $-2.0 \mathrm{~V}(\mathrm{SCE})$ for a 5 -min period, a suitable cathodic potential sufficient to cause dissolution of existing air-formed passive films..$^{20}$ Current-time curves were then monitored over a 90-min period at the required passivating potential. In potentiodynamic tests the potential was scanned in the anodic direction, from the initial polarizing potential, at a rate of $1 \mathrm{mV} \mathrm{s}^{-1}$. In order to prevent the introduction of iodine into the working solution, which is formed at the auxiliary electrodes during cathodic polarization in iodide solution, it was necessary to separate the auxiliary electrodes from the working solution by means of a double compartment cell which allowed contact between both compartments through a frit.

In activation studies, $50 \mathrm{ml}$ of a freshly prepared activator-containing solution $\left[\mathrm{In}_{2}\left(\mathrm{SO}_{4}\right)_{3}\right.$ solution] was added to the working electrolyte $(100 \mathrm{ml})$, after a given passivation period. Concentrations were adjusted so that the halide concentration before and after addition was maintained constant. The resultant solution was mixed by agitation with nitrogen, and the current-time transients recorded as a continuous function of time. Scanning electron microscopy (SEM) coupled with energy dispersive X-ray analysis (EDAX) was used to study the surface morphology of the corroded specimens and for qualitative analysis.

All potentials quoted are with respect to the saturated calomel electrode.

\section{EXPERIMENTAL RESULTS}

An initial estimation of the pitting potentials in $\mathrm{Cl}^{-}, \mathrm{Br}^{-}$and $\mathrm{I}^{-}$solutions, adjusted to the same $\mathrm{pH}$, was obtained from potentiodynamic polarization tests. The plots recorded in $0.5 \mathrm{M}$ solutions adjusted to a $\mathrm{pH}$ of 7.0 are shown in Fig. 1. The passive current density measured in the presence of each of the halides is similar, of the order of $3 \mu \mathrm{A} \mathrm{cm}^{-1}$, implying very little variation in the passive behaviour of aluminium in halide solutions. More noble pitting potentials are measured as the highly aggressive chloride anion is replaced successively by bromide and iodide anions, in agreement with previous reports. ${ }^{21}$

The influence of the nature of the halide anion and the applied potential on the pitting process was evident more clearly from potentiostatic tests, where meta-stable 

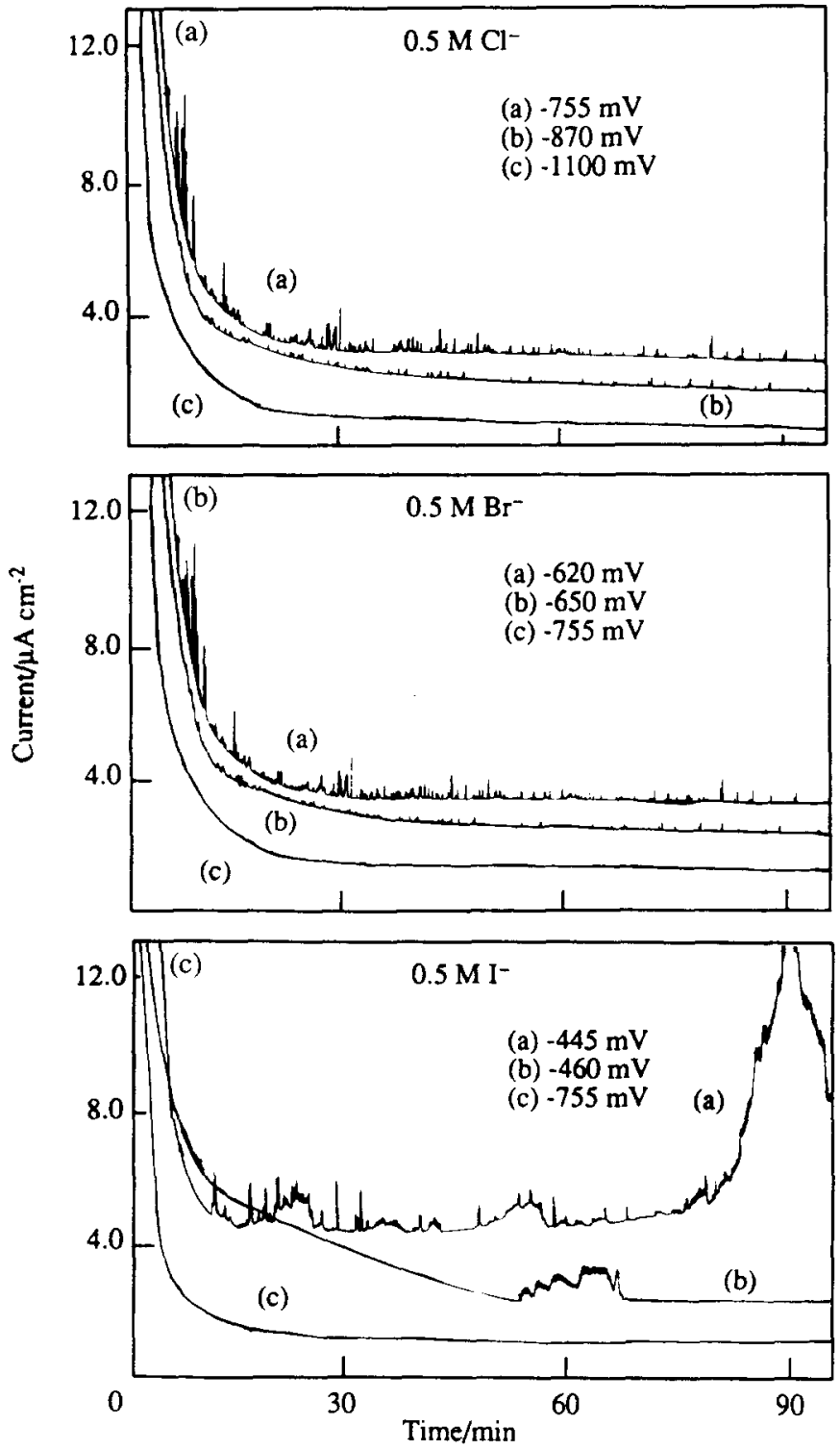

FIG. 2. (a) Current-time curves of $99.999 \%$ aluminium in neutral $0.5 \mathrm{M} \mathrm{NaCl}$ solutions at applied potentials of (a) $-755 \mathrm{mV}$ (SCE), (b) $-870 \mathrm{mV}$ (SCE) and (c) $-1100 \mathrm{mV}$ (SCE); (b) current-time curves of $99.999 \%$ aluminium in neutral $0.5 \mathrm{M} \mathrm{NaBr}$ solutions at applied potentials of (a) $-620 \mathrm{mV}(\mathrm{SCE})$, (b) $-650 \mathrm{mV}(\mathrm{SCE})$ and (c) $-755 \mathrm{mV}(\mathrm{SCE})$; (c) currenttime curves of $99.999 \%$ aluminium in neutral $0.5 \mathrm{M} \mathrm{NaI}$ solutions at applied potentials of (a) $-445 \mathrm{mV}(\mathrm{SCE}),(\mathrm{b})-460 \mathrm{mV}(\mathrm{SCE})$ and (c) $-755 \mathrm{mV}$ (SCE).

pit-initiation events could be detected clearly as fluctuations on the current-decay profiles. This is shown in Fig. 2(a), (b) and (c), where (a) demonstrates the effects of varying the potential applied to the test sample in a neutral $0.5 \mathrm{M} \mathrm{Cl}^{-}$solution, (b) refers to a neutral $0.5 \mathrm{M} \mathrm{Br}^{-}$solution and (c) a neutral $0.5 \mathrm{M} \mathrm{I}^{-}$electrolyte. It is clear that the passive film becomes more unstable as the applied potential is increased in 
the anodic direction. For each halide, the current fluctuations increase in terms of both frequency and magnitude and eventually a state is reached where a further increase in potential leads to complete activation. The aggressive order of the halides is again clear; potential conditions which are conducive to a high frequency of activation events in chloride media, for example test samples passivated at $-755 \mathrm{mV}$ (SCE), yield a stable passive state in both bromide and iodide solutions. Similarly, test samples remain more passive in iodide than in bromide solutions on application of the same potential. The important point to note here is the difference in the superimposed fluctuations observed in $\mathrm{I}^{-}$solutions and in $\mathrm{Cl}^{-}$and $\mathrm{Br}^{-}$ solutions. The rate of repassivation is much reduced in the presence of iodide: the overall trend is an increase in the size and duration of the current increases.

This contrast is demonstrated, also, in Fig. 3(a), (b) and (c) where the currenttime behaviour in $2.0 \mathrm{M} \mathrm{Cl}^{-}, \mathrm{Br}^{-}$and $\mathrm{I}^{-}$electrolytes are compared under corresponding potential conditions, i.e. where a constant difference $(45 \mathrm{mV})$ between the applied passivation potential and the potential which corresponds to complete activation is maintained for each system. As shown by the inset detail, the transients are essentially identical in both $\mathrm{Br}^{-}$and $\mathrm{Cl}^{-}$solutions, but quite different in $\mathrm{I}^{-}$ media. Even though the activation events in $\mathrm{I}^{-}$solutions appear to be less frequent, at least in the early stages of passivation, once an activation event is initiated repassivation seems to be slower.

Current-time tests monitored over more extended periods of time are shown for a $0.5 \mathrm{M} \mathrm{Cl}^{-}$and $0.5 \mathrm{M} \mathrm{I}^{-}$solution in Fig. 4(a) and (b) respectively. Corresponding potentials of -755 and $-490 \mathrm{mV}(\mathrm{SCE})$ were applied to the test samples. The passive current density increases with a concomitant increase in the frequency and size of the current fluctuations for the test sample passivated in the iodide electrolyte. In contrast, the activation events gradually disappear with time in the $0.5 \mathrm{M} \mathrm{Cl}^{-}$ solution. The more extensive attack experienced in iodide solutions is evident from a comparison of the SEM micrographs shown in Fig. 5(a) and (b). Crystallographic attack is evident in the $\mathrm{Cl}^{-}$electrolyte where as the surface appears to have undergone more general, or more extensive attack, in iodide solutions.

The striking difference observed in $\mathrm{Cl}^{-}$and $\mathrm{I}^{-}$solutions, over more extended passivation periods, was examined further by studying the influence of the exposure time, or immersion time, in the test solution on the pitting potential. Similarly prepared specimens were immersed in a $0.5 \mathrm{M} \mathrm{Cl}^{-}$or $0.5 \mathrm{M} \mathrm{I}^{-}$solution and allowed to stand under open circuit conditions for various exposure periods $\left(1-10^{3} \mathrm{~min}\right)$. The specimens were then polarized potentiodynamically in the anodic direction at a scan rate of $1 \mathrm{mV} \mathrm{s}^{-1}$ in a freshly prepared solution. The initial potential was selected as $-1300 \mathrm{mV}$ and a prepolarization period or cathodic activation was not used. This ensured that oxide dissolution due to local alkalization did not occur in the cathodic region. The variation of the pitting potential for both solutions is shown in Fig. 6 . Clearly, it is evident that the increased exposure periods give rise to more noble breakdown potentials in the chloride electrolyte, however, no significant ennoblement was observed in the iodide solution.

An increase in the halide concentration at a given applied potential gave rise to more intense activation events, as expected. However, variation of the NaI concentration in the range $0.01-0.2 \mathrm{M}$ gave different profiles. Figure 7 presents the currentdecay profiles recorded in a $0.1 \mathrm{M} \mathrm{NaI}$ solution at $-490 \mathrm{mV}$ (SCE) as a function of $\mathrm{pH}$. The initial current decay is followed by a $\mathrm{pH}$-dependent increase to a maximum 

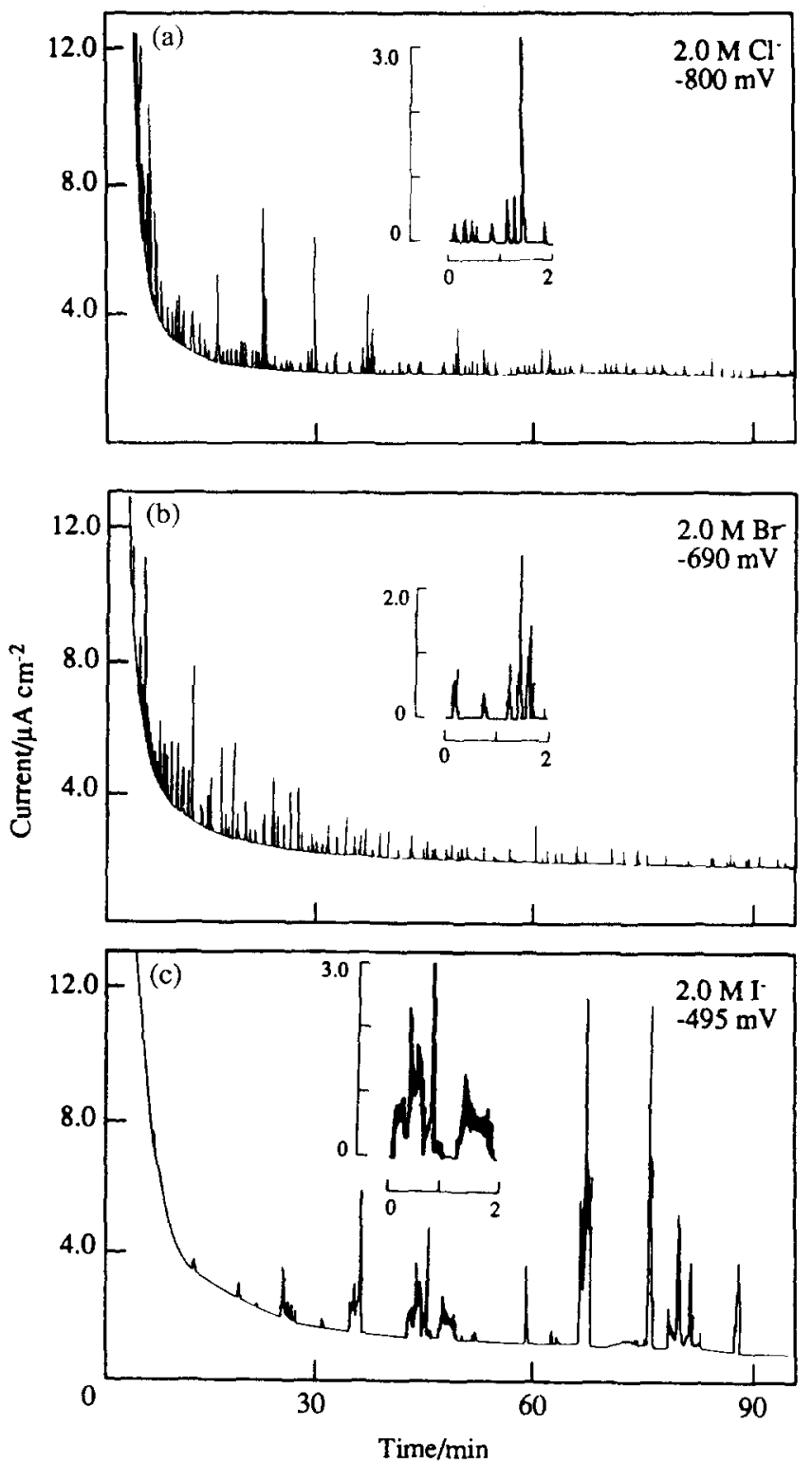

FIG. 3. (a) Current-time curve of $99.999 \%$ aluminium passivated at $-800 \mathrm{mV}$ (SCE) in a $2.0 \mathrm{M} \mathrm{NaCl}$ solution adjusted to a $\mathrm{pH}$ of 7.0 ; (b) current-time curve of $99.999 \%$ aluminium passivated at $-690 \mathrm{mV}(\mathrm{SCE})$ in a $2.0 \mathrm{M} \mathrm{NaBr}$ solution adjusted to a $\mathrm{pH}$ of 7.0 ; (c) current-time curve of $99.999 \%$ aluminium passivated at $-495 \mathrm{mV}(\mathrm{SCE})$ in a $2.0 \mathrm{M} \mathrm{NaI}$ solution adjusted to a $\mathrm{pH}$ of 7.0 .

value, and a subsequent logarithmic decay to current densities comparable to those recorded in chloride or bromide solutions.

In order to examine further the variation in the electrochemical behaviour of aluminium in halide solutions, electrochemical tests were carried out where the aluminium surface was activated by indium ions. With halide concentrations of $0.5 \mathrm{M}$ 


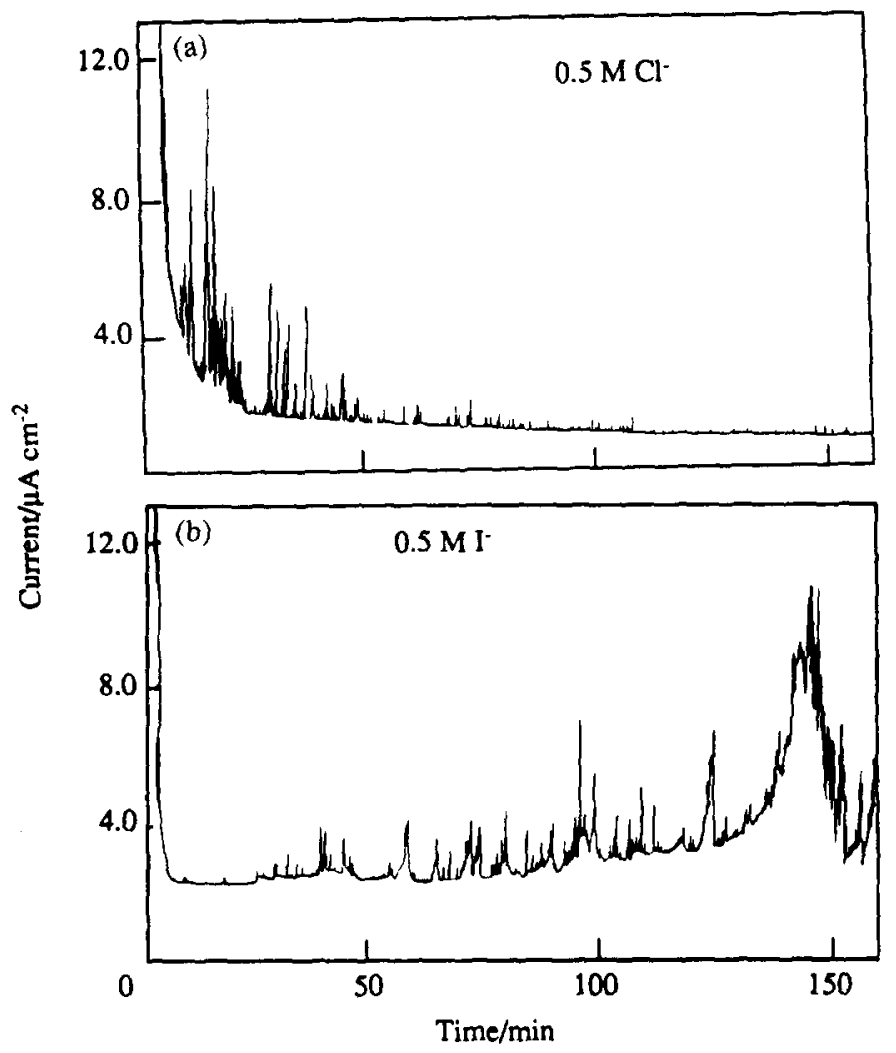

Fig. 4. (a) Current-time plot of $99.999 \%$ aluminium passivated at $-755 \mathrm{mV}$ (SCE) in a $0.5 \mathrm{M} \mathrm{NaCl}$ electrolyte over a 150 -min period; (b) current-time plot of $99.999 \%$ aluminium passivated at $-450 \mathrm{mV}(\mathrm{SCE})$ in a $0.5 \mathrm{M} \mathrm{NaI}$ solution over a $150-\mathrm{min}$ period.

and indium ion concentrations of $0.01 \mathrm{M}$ the breakdown potentials measured, using potentiodynamic techniques, in $\mathrm{Cl}^{-}, \mathrm{Br}^{-}$and $\mathrm{I}^{-}$media were $-1100,-1035$ and $-920 \mathrm{mV}(\mathrm{SCE})$ respectively compared to $-720,-560$ and $-410 \mathrm{mV}(\mathrm{SCE})$ in the absence of indium ions. The aggressive order of the halides was maintained, and each halide appeared to give rise to the same degree of activity. Using the potentiostatic technique, described in the experimental section, some variation in the aggressiveness of the halide anions was evident. Figure 8 compares the current-time behaviour in $0.5 \mathrm{M} \mathrm{Cl}^{-}$and $0.5 \mathrm{M} \mathrm{I}^{-}$solutions on addition of $1 \times 10^{-3}$ and $0.0125 \mathrm{M} \mathrm{In}^{3+}$ after a $25 \mathrm{~min}$ passivation period. The potentials applied to the specimens were -1050 and $-900 \mathrm{mV}(\mathrm{SCE})$ respectively. This ensured that a constant difference between the applied passivation potentials and breakdown potentials in the presence of $\mathrm{In}^{3+}$ ions was maintained. On addition of the activator ions a net cathodic current was measured, the magnitude being dependent on the halide anion. After the elapse of a certain induction period, $\tau$, the current increased in a ragged fashion which may be interpreted as resulting from a dynamic dissolution-repassivation process. In the chloride-containing electrolyte activation predominated, however, in the iodide solution, the surface appeared to regain its passivity as time progressed.

The more permanent activity imparted by chloride anions is evident again from the open-circuit potential-time plots shown in Fig. 9. The aluminium samples were 

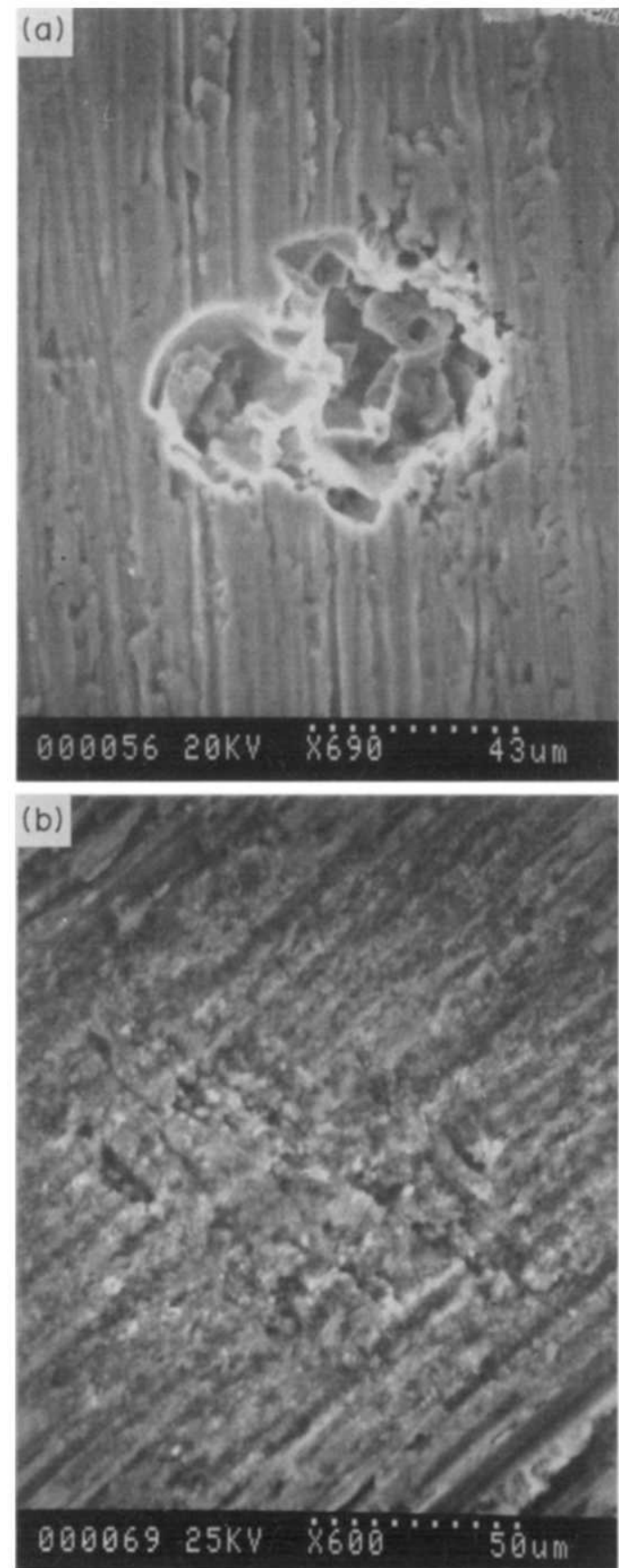

FIG. 5. SEM micrograph of aluminium following potentiostatic testing, (a) refers to aluminium passivated at $-755 \mathrm{mV}(\mathrm{SCE})$ in a $0.5 \mathrm{M} \mathrm{NaCl}$ solution for a 100 -min period; (b) refers to aluminium passivated at $-450 \mathrm{mV}(\mathrm{SCE})$ in a $0.5 \mathrm{M} \mathrm{NaI}$ solution for a $100 \mathrm{~min}$ period. 

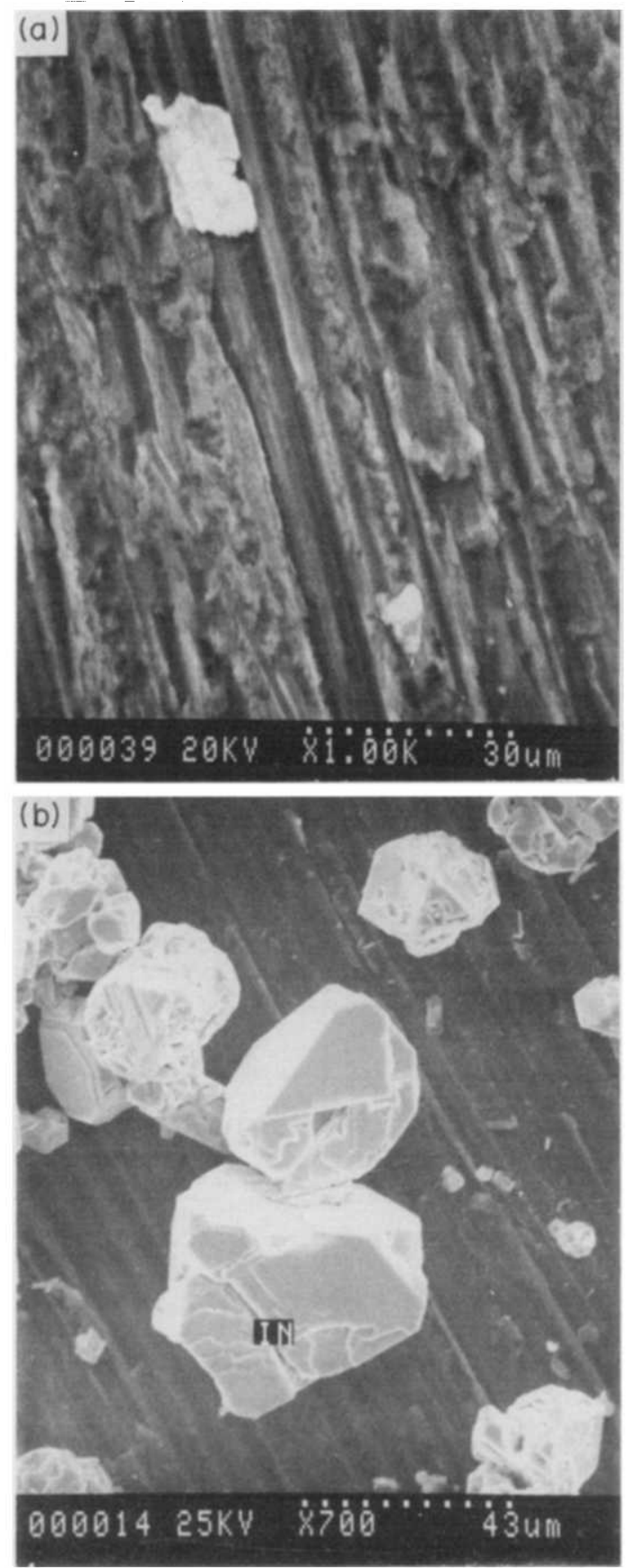

FIG. 10. SEM micrographs for aluminium polarized in (a) a $0.5 \mathrm{M} \mathrm{NaCl}$ solution containing $0.0125 \mathrm{M} \mathrm{In}^{3+}$ and (b) a $0.5 \mathrm{M} \mathrm{NaBr}$ solution containing $0.0125 \mathrm{M} \mathrm{In}^{3+}$. 


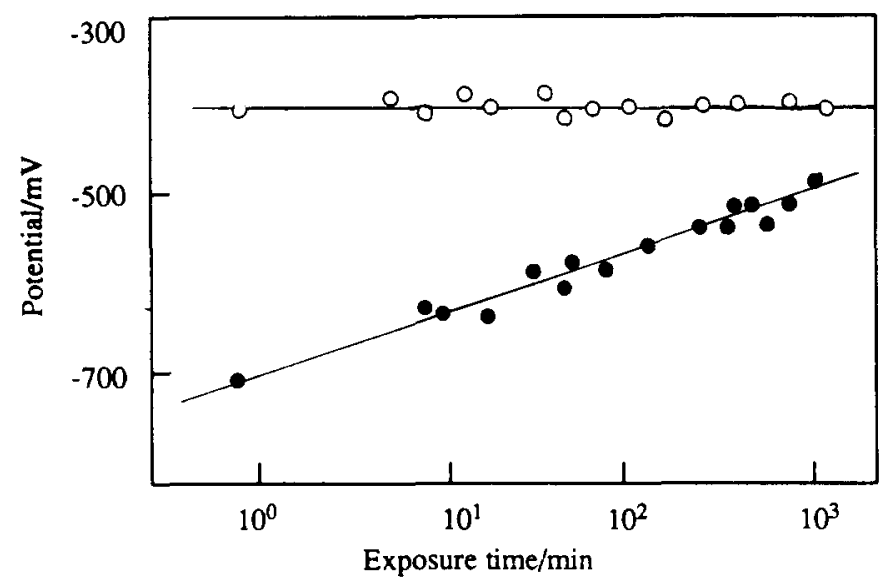

Fig. 6. Plot of the pitting potential ( $\mathrm{mV}$ ), against the exposure (immersion) time ( $\mathrm{min}$ ) for - aluminium immersed in a neutral $0.5 \mathrm{M} \mathrm{NaCl}$ solution, $\mathrm{O}$ aluminium immersed in a $0.5 \mathrm{M}$ NaI solution. The potential was scanned from $-1300 \mathrm{mV}(\mathrm{SCE})$ up to the breakdown potential.

activated initially in a chloride and indium solution (ensuring efficient deposition of indium at the electrode surface) and then transferred to an iodide and a chloride solution. Activation was maintained in the chloride environment whereas the potential displayed only intermittent oscillations in the active direction in the iodide electrolyte, as shown in the figure. Similar results were obtained in bromide solutions.

It seemed, also, to be more difficult to initiate attack in either $\mathrm{Br}^{-}$or I $\mathrm{I}^{-}$solutions. For example, the induction period, $\tau$, exceeded $400 \mathrm{~min}$ at $-800 \mathrm{mV}(\mathrm{SCE})$ with a $0.0125 \mathrm{M} \mathrm{In}^{3+}$ addition to a $0.5 \mathrm{M} \mathrm{Br}^{-}$solution, whereas $\tau$ was measured as 90 min in a $0.5 \mathrm{M} \mathrm{Cl}^{-}$solution. A much higher cathodic current was noted also in the $\mathrm{Br}$ electrolyte. SEM-EDAX analysis of test samples under these conditions revealed a

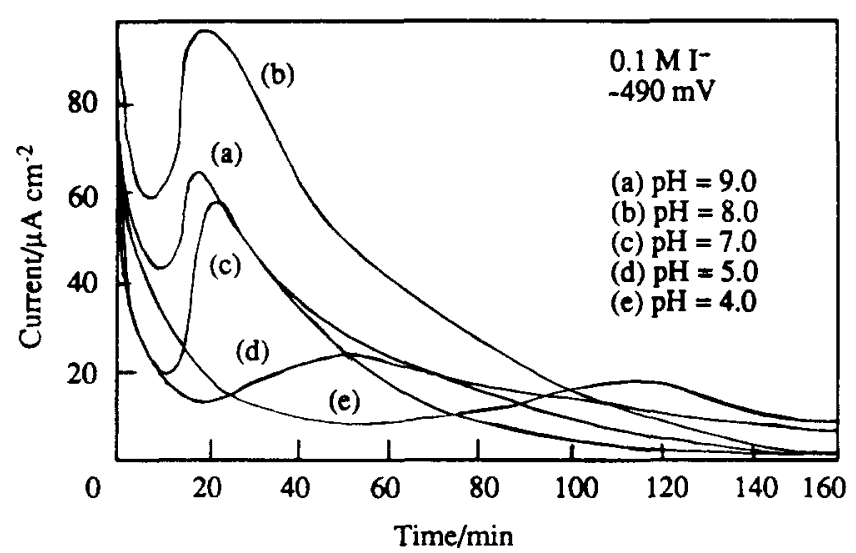

Fig. 7. Current-time curves as a function of $\mathrm{pH}$ for aluminium passivated in a $0.1 \mathrm{M} \mathrm{NaI}$ solution at $-490 \mathrm{mV}(\mathrm{SCE})$, (a) $\mathrm{pH}=9.0$; (b) $\mathrm{pH}=8.0$; (c) $\mathrm{pH}=7.0$; (d) $\mathrm{pH}=5.0$; (e) $\mathrm{pH}=4.0$. 

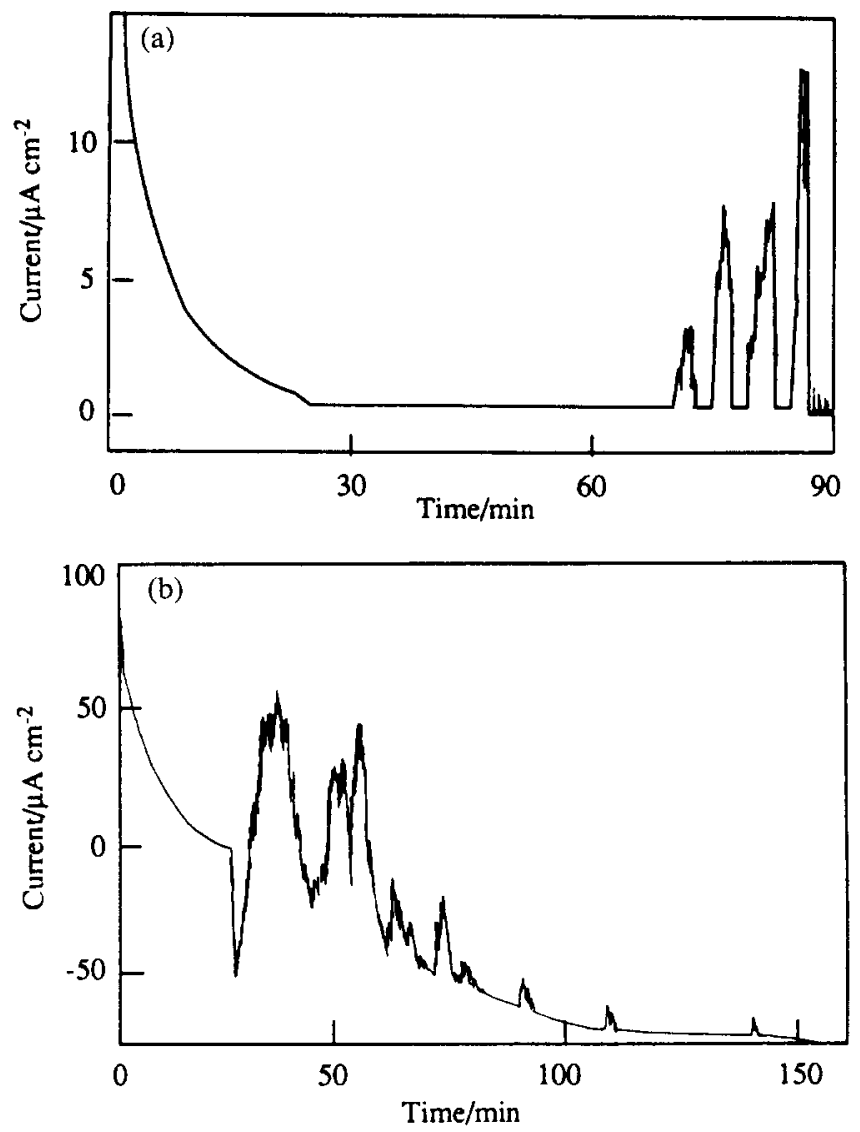

Fig. 8. Potentiostatic activation experiments, aluminium test samples were passivated in the test solution for a 25 -min period and then $\mathrm{In}^{3+}$ ions were added to the test solution: (a) aluminium passivated in a $0.5 \mathrm{M} \mathrm{NaCl}$ solution at $-1050 \mathrm{mV}(\mathrm{SCE})$ with the addition of $1 \times 10^{-3} \mathrm{M} \mathrm{In}^{3+}$; (b) aluminium passivated in a $0.5 \mathrm{M} \mathrm{NaI}$ solution at $-900 \mathrm{mV}(\mathrm{SCE})$ with the addition of $0.0125 \mathrm{M} \mathrm{In}^{3+}$.

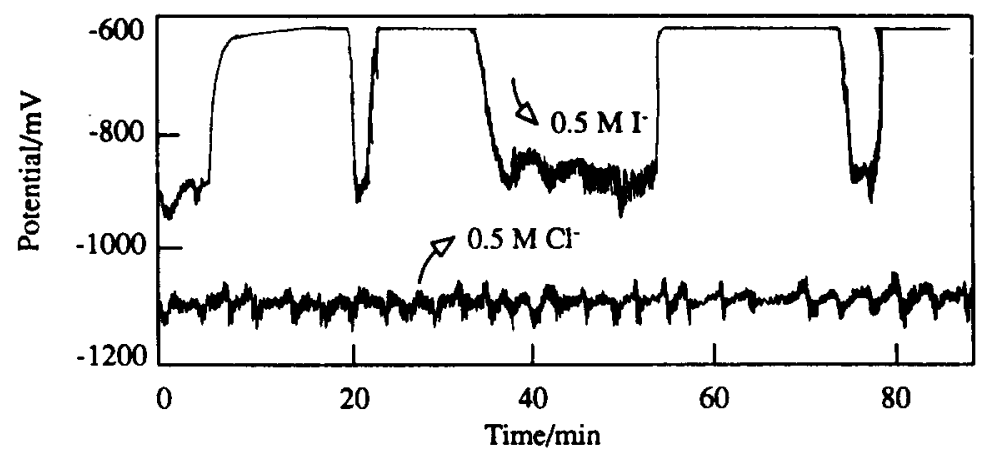

Fig. 9. Open-circuit potential behaviour as a function of time for aluminium initially activated in an indium-containing solution and then transferred to a $0.5 \mathrm{M} \mathrm{NaI}$ and $0.5 \mathrm{M}$ $\mathrm{NaCl}$ solution. 
large amount of indium at the surface of the sample in the bromide-containing electrolyte as shown in Fig. 10(b), where the light coloured crystalline units were found to consist exclusively of indium. These units were attached only loosely at the surface and could be removed easily with ultrasonic cleaning. A similar effect was observed in $\mathrm{I}^{-}$solutions. In contrast, the indium appeared to be securely embedded in the surface following polarization in the chloride electrolyte, as shown in Fig. $10(\mathrm{a})$, and could be removed only on mechanical polishing.

\section{DISCUSSION}

Although the polarization plots (Fig. 1) are essentially identical for each halide, the potentiostatic data presented highlight the differences in the processes of pitting of aluminium in chloride or bromide and iodide solutions. These potentiostatic measurements also have the added advantage that the initial prepolarization at cathodic potentials is sufficient to cause dissolution of the existing air-formed films and consequently, induction periods ${ }^{8,22}$ arising as a result of air-formed films, do not affect these measurements. Secondly, a much longer testing period is employed in comparison to the potentiodynamic results, and more effects of the various halides are observed. This leads to a different finding to that proposed by Baumgartner and $K_{\text {Kaesche }}{ }^{21}$ who found no significant difference, other than the morphology of the corroded surfaces, between the pitting behaviour of aluminium in $\mathrm{Cl}^{-}$or $\mathrm{Br}^{-}$and $\mathrm{I}^{-}$ electrolytes. They found that the electrochemical behaviour of aluminium in $\mathrm{Cl}^{-}$, $\mathrm{Br}^{-}$and $\mathrm{I}^{-}$solutions was similar but that both (100) and (110) planes were involved in forming the pit structure in iodide solutions, producing octahedral etch pits whereas only (100) planes were entailed in the pitting of aluminium in bromide or chloride electrolytes.

Before the variations in the pitting processes of aluminium in chloride and iodide are discussed it is first necessary to outline the sequence of events that lead to pitting of aluminium in chloride solutions. Much work has been carried out in this area, and although the evidence for chloride adsorption at the metal surface, as a precursor to pit initiation, remains controversial, ${ }^{23-26}$ the results presented in this communication, particularly the potentiostatic data, are best explained in terms of adsorption of the aggressive halide at defective centres on the surface, and then reaction of the adsorbed anion with aluminium in the lattice through complex formation. ${ }^{1}$ The immediate and random development of current fluctuations on the decay profiles, in bromide and chloride solutions, conforms with the view that activation begins at specific sites at the surface. $9,10,27$ The intensification of the fluctuations with an increase in potential or halide concentration supports the concept that adsorption is connected with the surface charge ${ }^{3}$ where the influence of potential may be to move the surface above the point of zero charge, $E_{\mathrm{pzc}}$, and increasing halide concentration to move the $E_{\mathrm{pzc}}$ in the active direction. ${ }^{28}$ The film improvement observed in the bromide and chloride solutions (Fig. 4) may be explained in terms of an oxide transformation process where the adsorbed halide forms a series of oxyhydroxo- and halocomplexes with aluminium. These complex species may be transformed to $\alpha-\mathrm{Al}(\mathrm{OH})_{3}$ or the stable hydrated oxide $\gamma-\mathrm{Al}_{2} \mathrm{O}_{3} \cdot 3 \mathrm{H}_{2} \mathrm{O} .{ }^{1}$ This resultant hydrated oxide should be more resistant to attack which would explain the disappearance of fluctuations with extended passivation periods (Fig. 4a) and the ennoblement of the pitting potential on prolonged immersion in the chloride test solution (Fig. 6). Supporting data have been published by Tomscanyi et al. ${ }^{2}$ where the excess surface 
concentration of chloride at the surface, measured from radiotracer techniques, was observed to fall to very low levels after several hours. This is in agreement with the idea that the adsorbed chloride forms a series of complex species which are then transformed into the hydrated oxide.

It appears that a similar sequence of events occurs in iodide solutions but that the oxidation of iodide to liberate iodine is a complicating feature. Iodide is known to undergo spontaneous oxidation in the presence of oxygen to liberate iodine.

$$
4 \mathrm{I}^{-}+\mathrm{O}_{2}+2 \mathrm{H}_{2} \mathrm{O}=2 \mathrm{I}_{2}+4 \mathrm{OH}^{-} \text {. }
$$

It seems that the liberated iodine rather than the iodide anion is responsible for the overall film instability observed with iodide solutions, the gradual trend being towards a more general type of attack. The protracted activation periods (Figs 2 and 4) are indicative of more extensive attack by iodide, or the build-up of a highly aggressive solution in the pit interior which inhibits repassivation. The constancy of the pitting potential with immersion period (Fig. 6) suggests that the passive film is under constant attack by iodide. The iodocomplexes transformed at the interface into more favourable hydroxo complexes provide a more resistant film, however, this film is attacked and dissolved by the aggressive iodide solution, and thus the advantageous consequences of these chemical transformations are not realized fully. The attainment of a highly aggressive iodide solution, which would account for these observations, is probably associated with changes in the electrolytic environment, particularly reduction of the $\mathrm{pH}$. This would explain the inhibition towards repassivation as reduction in the $\mathrm{pH}$ of an environment is known to prevent passivation. ${ }^{29,30}$ The extensive attack evident in the micrograph in Fig. 5 is consistent also with an acidic environment. The hydrolysis of corrosion products alone should not give rise to a sufficient drop in the $\mathrm{pH}$ since similar events should occur in chloride or bromide systems. In addition dissolved iodine in the iodide electrolye may lead to the formation of hypoiodous and iodic acids which in conjunction with the iodide anions provide a sufficiently acidic and aggressive environment. A possible mechanism for these reactions or events is outlined as follows.

The initial iodide solution dissolves iodine giving rise to the $\mathrm{I}_{3}^{-}$species with low concentrations of iodine. The $\mathrm{I}_{3}^{-}$then disproportionates in accordance with the equilibrium:

$$
2 \mathrm{I}_{3}^{-}+2 \mathrm{H}_{2} \mathrm{O}=2 \mathrm{HIO}+2 \mathrm{HI}+2 \mathrm{I}^{-}
$$

to form hypoiodous and iodic acid. HIO will disproportionate further being unstable:

$$
\begin{array}{ll}
5 \mathrm{HIO}=2 \mathrm{I}_{2}+\mathrm{IO}_{3}^{-}+1 \mathrm{H}^{+}+2 \mathrm{H}_{2} \mathrm{O} & \Delta G=-121 \mathrm{~kJ} \mathrm{~mol}^{-1} \\
3 \mathrm{IO}^{-}=2 \mathrm{I}^{-}+\mathrm{IO}_{3}^{-} & \Delta G=-134 \mathrm{~kJ} \mathrm{~mol}^{-1} .
\end{array}
$$

These reactions should provide an acidic environment which together with the complex iodide species would furnish an aggressive medium. The development of an acidic vicinity is supported also by the work of Beavers et al. ${ }^{14}$ where a drop in the $\mathrm{pH}$ of distilled water in contact with iodine crystals on iron and nickel is reported. 
The current maxima and minima observed in Fig. 7 possibly arise as a result of the interaction of $\mathrm{I}_{2}$ with the developing passive film. Destabilization of the developing film is quite substantial in the early stages, however, after a certain period the oxidereformation process predominates and a relatively stable film is formed. A possible mechanism for this destabilization and reformation may involve the adsorption of iodine at the surface of an essentially oxide-free aluminium electrode and the formation of an aluminium iodide complex species, $\mathrm{AlI}_{3}$, in accordance with the equation:

$$
\mathrm{Al}+5 / 2 \mathrm{I}_{2}+\mathrm{H}_{2} \mathrm{O}=\mathrm{AlI}_{3}+\mathrm{HOI}+\mathrm{HI} .
$$

Such a process would explain, also, the pronounced $\mathrm{pH}$ influence. After a certain period of time this complex will dissociate, generating a free surface which then can participate in the normal sequence of oxide-formation reactions. The onset of the second current decay is consistent with the removal of iodine and complexed iodide species from the surface. The current decay in this region fits well to the equation of Nisanciouglu and Holtan for the bidimensional growth of an oxide film: ${ }^{31}$

$$
I_{\infty}-I=K \mathrm{e}^{-\tau / t}
$$

where $\tau$, the time constant for decay, is inversely proportional to the rate of attack. As expected the rate of repassivation increases with increasing $\mathrm{pH}$ of the test solution.

Further evidence for attack by iodine was obtained from subsidiary experiments where it was found that the current maxima and minima were less pronounced if the working solution was de-oxygenated, thereby decreasing the iodine concentration, or if a supporting anion was added, e.g. chloride or sulphate, facilitating competitive adsorption between iodine and the supporting anion at the metal-solution interface. Similarly, the addition of iodine, e.g. 0.001-0.01 M, to the iodide working solution leads to more prominent current maxima denoting greater interaction between iodine and the electrode.

The fact that iodine has a substantial effect only in the early stages of film development and that once the current decays to a low value the surface remains passive regardless of the iodine concentration in solution, provided that the applied potential is in the passive region (Fig. 7), leads to the inference that iodine attacks the base metal and not the oxide film. This is further supported by current-time tests carried out with aluminium electrodes which were not cathodically activated at the outset of the test to remove the existing air-formed film and aluminium electrodes which were previously anodized in acid sulphate solutions. In both cases, the presence of the oxide film prevented attack of the base metal and current maxima and minima were essentially absent, the effect of the oxide being more pronounced with the anodized surface. Nevertheless, the build-up of an iodide solution can attack the passive film, as is evident from Fig. 4(b).

Other differences between the activity of the halides is evident from the activation studies carried out with indium ions. The activation of aluminium by activator ions in solution arises as a result of the electrochemical deposition of the activator on to the metal surface with subsequent activation. ${ }^{17-19}$ The halides participate in the activation process to different extents as shown in Figs 9 and 10. This is due to two factors: the role played by the halide anion once sufficient activator has been deposited, and the influence of the halide anion on the rate of activator 
deposition. The rate of activator deposition is dependent on the nature of the surface, which is dependent further on the degree of halide adsorption or halide complexation. The larger induction periods measured in bromide solutions compared with those measured in chloride solutions, under the same conditions, are due, most likely, to greater adsorption of bromide at flawed areas which are also the sites of activator deposition. ${ }^{19}$ Less efficient deposition of the activator in bromide solutions is evident, also, from a comparison of the electron micrographs in Fig. 10 where the loosely attached deposits are unable to activate the surface.

Once activation is initiated iodide and, to a lesser extent, bromide anions impart a somewhat passivating effect. Activation cannot be maintained at a sufficiently high rate in the presence of these anions, even if indium is initially deposited at the surface (Figs 9 and 10). The data obtained in iodide solutions are again complicated (i) by the formation of iodine, promoted by hydrolysis of the indium ions which leads to an even further reduction in $\mathrm{pH}$ and a greater concentration of iodine, and (ii) by the formation of iodic and hypoiodous acids which may reduce the effective concentration of iodide. This alone is not sufficient to explain the rapid loss of activity on immersion in an iodide solution (Fig. 9), however.

The interaction of iodine with aluminium seems to be a reasonable explanation for the current maxima and minima observed in Fig. 7 and the gradual deterioration of the passive film (Figs $4 \mathrm{~b}$ and 6). It should be mentioned, however, that current transients with an initial minimum or arrest have previously been reported in the literature. ${ }^{32}$ These reported transients differ from the present results in the sense that the transients survive over a 12 -s period only. The explanation offered by Hurlen et $a l .{ }^{32}$ is based on the fact that metal ion transfer depends on the kink density in the metal surface, which increases with electric field strength by a relaxation process. A potential step results in a sharp increase in field strength, giving the initial rise in current with time, while increasing film thickness gives rise to decreasing field strength leading to the subsequent fall in current with time. Although this relaxation process will occur in the present tests, it should only survive for a few seconds and realistically cannot be used to explain the present current transients obtained with low iodide concentrations.

1. R. T. Foley, Corrosion 42, 277 (1986).

2. L. Tomcsanyi, K. Varga, I. Bartik, G. Horanyi and E. Maleczki, Electrochim. Acta 43, 855 (1989).

3. P. M. Natishan, E. McCafferty and G. K. Hubler, J. electrochem. Soc. 135, 321 (1988).

4. H. KAESCHE, Werskt. Korros. 39, 153 (1988).

5. F. Ovari, L. Tomcsanyi and T. Turmezey, Electrochim. Acta 33, 323 (1988).

6. H. Shin and F. Mansfeld, Corrosion 45, 610 (1989).

7. M. B. Ives, 10th Int. Congr. Metallic Corrosion, p. 3235 (1987).

8. Z. A. Foroulis and M. J. Thubrikar, J. electrochem. Soc. 122, 1296 (1976).

9. G. E. Thompson, R. C. Furneaux and G. C. Wood, Corros. Sci. 18, 481 (1987).

10. M. Janik-Czachor, G. C. Wood and G. E. Thompson, Br. Corros. J. 15, 154 (1980).

11. A. K. Vigh, Mater. Chem. Phys. 20, 371 (1988).

12. R. Guo and M. B. IvEs, Corrosion 46. 125 (1990).

13. T. H. Nguyen and R. T. Foley, J. electrochem. Soc. 126, 1855 (1979).

14. A. Beavers, W. E. Berry and J. C. Griess, Int. Congr. Metallic Corros., Toronto, vol. 3, p. 274 (1984).

15. W. J. Bohnstedt, J. Power Sources 5, 245 (1980).

16. C. D. S. Tuck, J. A. Hunter and G. M. Scamans, J. electrochem. Soc. 134, 2970 (1987).

17. M. C. Reboul, Ph. Gimenez and J. J. Rameau, Corrosion 40, 366 (1984). 
18. M. C. Reboul and M. C. Delatte, Mater. Perform. 19, 35 (1980).

19. W. M. Carroll and C. B. Breslin, Corros. Sci. 33, 1161 (1992).

20. P. Ll. Cabot, J. A. Garrido, E. Perez and J. Virgili, Corros. Sci. 26, 357 (1987).

21. M. Baumgartner and H. Kaesche, Werkst. Korros. 42, 158 (1991).

22. R. Nishimura, K. Kudo, Proc. 8th Int. Congr. Met. Corros., Mainz Dechema, Frankfurt am Main, vol. 1, p. 6 (1981).

23. J. Painor and J. Augustynski, J. electrochem. Soc. 123, 841 (1976).

24. M. F. Abd Rabbo, G. C. Wood, J. A. Richardson and C. K. Jackson, Corros. Sci. 14, 645 (1974).

25. M. F. Abd Rabbo, G. C. Wood, J. A. Richardson and C. K. Jackson, Corros. Sci. 16, 677 (1976).

26. D. M. Drazic, S. K. Zecevic, R. T. ATanasoski and A. R. Despic, Electrochim. Acta 28, 751 (1983).

27. A. D. Davydon, A. N. Kamkin and T. N. Roshchina, Electrochimija (Russ.) 14, 901 (1978).

28. R. J. Brigham, Corros. Sci. 29, 995 (1989).

29. J. R. Galvele, Corros. Sci. 21, 551 (1981).

30. J. R. Galvele and S. M. De Micheli, Corros. Sci. 10, 795 (1970).

31. K. Nisancioglu and H. Holtan, Corros. Sci. 19, 537 (1979).

32. T. Hurlen, H. Lian, O. S. Odegard and T. Valand, Electrochim. Acta 29, 579 (1984). 